\title{
Differential deposition of antimicrobial proteins in blue tit (Cyanistes caeruleus) clutches by laying order and male attractiveness
}

\author{
Liliana D'Alba • Matthew D. Shawkey • Peter Korsten • \\ Oscar Vedder • Sjouke A. Kingma • Jan Komdeur • \\ Steven R. Beissinger
}

Received: 9 December 2009/Revised: 30 January 2010 /Accepted: 1 February 2010 /Published online: 27 February 2010

(C) The Author(s) 2010. This article is published with open access at Springerlink.com

\begin{abstract}
Female birds can influence offspring fitness by varying the relative quantities of egg components they deposit within and between clutches. Antimicrobial proteins (lysozyme, ovotransferrin, and avidin) are significant components of the avian albumen and likely aid in defense of embryos from microbial infection. Within clutches, females may enhance antimicrobial defense of early-laid eggs to protect them from the high risk of infection incurred before the onset of incubation. Among entire clutches, females may invest more resources in young sired by more
\end{abstract}

Communicated by: J. Graves

L. D’Alba $(\square) \cdot$ M. D. Shawkey

Department of Biology and Integrated Bioscience Program,

University of Akron, Akron,

OH 44325-3908, USA

e-mail: liliana@uakron.edu

P. Korsten $\cdot$ O. Vedder $\cdot$ S. A. Kingma $\cdot$ J. Komdeur

Animal Ecology Group,

Centre for Ecological and Evolutionary Studies,

University of Groningen, P.O. Box 14,

9750 AA Haren, The Netherlands

\section{S. R. Beissinger}

Ecosystem Sciences Division,

Department of Environmental Science,

Policy and Management, University of California,

Berkeley, CA 94720, USA

\section{S. A. Kingma}

Max Planck Institute for Ornithology,

Vogelwarte Radolfzell, Schlossallee 2,

78315 Radolfzell, Germany

Present Address:

P. Korsten

Institute of Evolutionary Biology,

School of Biological Sciences, University of Edinburgh,

West Mains Road, Edinburgh EH9 3JT, UK attractive males because they have higher reproductive value. We tested these hypotheses by quantifying antimicrobial protein distribution within and among clutches in blue tit eggs. Contrary to our hypothesis, clutches showed no differential deposition of lysozyme or avidin within clutches, but eggs laid in the middle of the sequence had higher concentrations of ovotransferrin than eggs in the beginning and end. Consistent with our second hypothesis, we found that females produced eggs with higher concentrations of lysozyme (although not ovotransferrin or avidin) when mated to more attractive (more UV-reflective) males. Furthermore, females mated to polygynous males deposited less lysozyme than those mated to monogamous males. These data suggest that allocation of lysozyme at the clutch level may be a maternal effect mediated by male qualities.

Keywords Maternal effects · Antimicrobial proteins . Differential allocation $\cdot$ Egg infection

\section{Introduction}

Maternal effects are non-genetic factors that females can manipulate to influence the phenotype and fitness of their offspring (Mousseau and Fox 1998). In birds, females can adaptively modify egg composition through the differential deposition of specific components that influence offspring growth (e.g., hormones, Williams 1994) and that defend embryos from external pathogens capable of causing infection (Tranter and Board 1982). Females transfer a complex array of immune factors and antibiotic proteins to their eggs (Kowalczyk et al. 1985; Board et al. 1994). Lysozyme, ovotransferrin, and avidin are three of the best characterized and most abundant proteins in egg albumen that are thought to play an important role in defense against 
microbial infection (Tranter and Board 1982). Lysozyme can break down the polysaccharide walls of a broad spectrum of Gram-positive bacteria (Rogers and Perkins 1968). Ovotransferrin sequesters iron that is essential for bacterial growth and is a major egg white protein, representing $12 \%$ of chicken albumen protein (Li-Chan et al. 1995). Similarly, avidin makes biotin unavailable for microbes and thereby inhibits their growth (Board and Fuller 1974). These antimicrobials protect the egg from infectious bacteria entering through the shell and, after being swallowed with the rest of the albumen at hatching, can be used in immune defense by the hatchling for several days (Saino et al. 2002).

Egg production is energetically costly for mothers (see review in Williams 2005) and eggs with high protein content may be particularly costly because birds might be protein-limited (Reynolds et al. 2003; Ramsey and Houston 1998). Nevertheless, it is unclear if allocation of antimicrobial proteins to eggs is particularly costly for mothers in terms of energy and nutrients (Saino et al. 2002; Shawkey et al. 2008). Deposition of antimicrobials may reduce the amount of vitamins and other components that can be deposited in the albumen. Thus, defense against microbial invaders may be traded off against nutrition in avian eggs, and females may adaptively partition these components to individual eggs within a clutch or to entire clutches.

Egg viability can decline dramatically after 3 to 5 days of exposure to ambient conditions prior to the onset of full incubation (Arnold et al. 1987; Stoleson and Beissinger 1999; Beissinger et al. 2005). Non-incubated eggs experience greater microbial growth than incubated eggs and are more prone to infection by microbes (Cook et al. 2003, 2005a; Shawkey et al. 2009). Because earlier-laid eggs are frequently not immediately incubated and are exposed longer before full incubation than subsequently laid eggs, they may be more susceptible to microbial infection (Cook et al. 2003, 2005b; Shawkey et al. 2008). Selection may therefore favor higher levels of antimicrobial compounds in earlier-laid eggs compared to later-laid eggs (Saino et al. 2002, Shawkey et al. 2008), but Shawkey et al. (2008) found little evidence that lysozyme, avidin, or ovotransferrin concentrations declined with laying order in eight bird species. However, the exposure periods for first-laid eggs of most species in their study only ranged from 1 to 3 days, with the exception of one waterfowl species with an exposure period of 8 days. Examination of other species with long exposure periods is needed to further test this hypothesis.

While the extent of systematic variation within clutches is presently unclear, inter-female variation in antimicrobial concentration of entire clutches appears quite high (Saino et al. 2002; Shawkey et al. 2008). Variation in resource allocation among females may be due to differences in female phenotype (e.g., age or physical condition; Christians 2002) or to environmental conditions (Verboven et al. 2005). Females might also vary the quality of their eggs in relation to mate attractiveness. Indicator models of sexual selection postulate that male ornamentation has evolved under the influence of female preferences for traits that reliably reflect the quality of potential partners (Andersson 1994). Females may use male ornaments as indicators of direct benefits, like high parental investment or high quality territories, or as indicators of indirect benefits like genes for attractiveness or viability (Andersson 1994). Therefore, females might invest more in current reproduction when mated to more attractive partners (the differential allocation hypothesis, DAH; Burley 1986). A number of studies have supported the DAH (Burley 1988; reviewed in Sheldon 2000); for example, females mated to attractive males increase the size (Cunningham and Russell 2000; Velando et al. 2006) and number (Petrie and Williams 1993) of eggs they lay. They may also improve the quality of their offspring by producing eggs with more antioxidants (Williamson et al. 2006; Szigeti et al. 2007), testosterone (Gil et al. 1999; Loyau et al. 2007), and antibodies (Saino et al. 2002). As far as we are aware, no study has tested whether females differentially allocate antimicrobial compounds in a similar manner.

Here we test the hypotheses that female blue tits Cyanistes caeruleus deposit more antimicrobial proteins in earlier-laid eggs within their clutch and in clutches sired by more attractive males. Blue tits serve as an excellent study species for both questions. First, they lay large clutches (typically nine to 14 eggs) and generally do not begin full incubation until 1 day before the final egg is laid (Nilsson 2000), potentially exposing the first-laid egg for up to 13 days. Thus, we predicted a strong decrease in antimicrobial depositions with laying order. Second, the bright ornamental plumage color of male blue tits appears to be a sexually selected trait. Reflectance in ultraviolet wavelengths (UV) is related to male attractiveness and viability (Andersson et al. 1998; Sheldon et al. 1999; Delhey et al. 2003; Griffith et al. 2003), to maternal hormone deposition in eggs (Kingma et al. 2009), and to female provisioning of chicks (Limbourg et al. 2004; Johnsen et al. 2005). Moreover, polygynous males (found regularly in the species; Dhondt et al. 1983, Kempenaers 1993) are considered highly attractive individuals (Kempenaers 1994). Thus, based on the DAH, we predicted that females mated to more UV-reflective and or polygynous males would deposit more antimicrobial proteins in their eggs.

\section{Methods}

Study area, egg collection, and bird handling

The study was carried out in the breeding season of 2005 (April-June) in a population of blue tits breeding in nestboxes at "De Vosbergen" estate (ca. 50 ha; $53^{\circ} 08^{\prime} \mathrm{N}, 06^{\circ} 35^{\prime}$ E) near 
Groningen, The Netherlands. This population has been intensively studied since 2001 . The study area consists of patches of mixed deciduous and coniferous forest interspersed by open grassland.

All nest boxes were initially checked weekly and then were checked daily as soon as they contained completed nests. Newly laid eggs were individually marked with non-toxic markers. We collected eggs 2, 5, 7, and 9 from each brood $(n=$ 44 clutches) on the day they were laid and immediately replaced them with plastic dummy eggs. Collected eggs were incubated for $72 \mathrm{~h}$ in an incubator at $35^{\circ} \mathrm{C}$ to induce embryonic development for extraction of DNA for molecular sexing. Although fertility of eggs in this study population is normally high (93\%; Magrath et al. 2009), embryos failed to develop likely because of a deficient artificial incubation protocol, including a somewhat low temperature and lack of humidity control. Incubation at this temperature increases enzymatic activity and thus may have some effect on the enzymes themselves. However, all eggs were treated equally and thus, should have been affected equally. After incubation, eggs were stored individually in sealed plastic bags at $-20^{\circ} \mathrm{C}$ until they were assayed for their antimicrobial contents.

Blue tit parents were captured inside their nestbox using a spring trap 6-10 days after hatching and were transported in a dark bird bag to the nearby field station, where the reflectance of their crown plumage was measured (see below). We also measured body mass (to the nearest $0.1 \mathrm{~g}$ using a $30 \mathrm{~g}$ spring balance). Because body mass varied with time of the day $(r=0.31, p=0.004, n=84)$, the residual mass after correcting for time of weighing was used in analyses. We determined parental age ( 1 or $>1$ year) based on the color of the primary coverts following Svensson (1992). Birds were released in their own territory after the measurements. Males captured at two different nestboxes were defined as polygynous. As we identified males at all nest boxes, males could be reliably assigned as socially monogamous or polygynous.

\section{Crown reflectance measurements}

Spectral reflectance of the crown feathers was measured with a USB-2000 spectrophotometer with illumination by a DH2000 deuterium-halogen light source (both Avantes, Eerbeek, The Netherlands). The measuring probe was held at a right angle against the plumage so that both illumination and recording were at a $90^{\circ}$ angle to the feathers. We then took five replicate readings and smoothed these reflectance spectra by calculating the running mean over $10 \mathrm{~nm}$ intervals. Following previous studies of crown coloration in blue tits (Andersson et al. 1998; Sheldon et al. 1999; Korsten et al. 2006), we calculated three indices describing the variation in crown coloration-"brightness," "hue," and "UV chroma"-from each reflectance spectrum and averaged these across the five replicate spectra. "Brightness" was the sum of reflectance between 320 and $700 \mathrm{~nm}\left(R_{320-700}\right)$, which corresponds to the spectral range visible to blue tits (Hart et al. 2000). "Hue" was the wavelength of maximum reflectance, $\lambda\left(R_{\max }\right)$. "UV chroma" was the sum of reflectance between 320 and $400 \mathrm{~nm}$ divided by the sum of reflectance between 320 and $700 \mathrm{~nm}\left(R_{320-400} / R_{320-700}\right)$. See Korsten et al. (2007) for estimates of the repeatability of these measures (varying between 0.50 and 0.75 ).

The capture of males $(n=40)$ and females $(n=44)$ for crown reflectance measurements occurred within relatively a short period (12 April to 18 June), leading to little variation in crown feather wear (crown coloration was not significantly related to the date of capture in either males (brightness: $r=0.03, p=0.81$; hue: $r=0.25, p=0.12$; UV chroma: $r=-0.19, p=0.21$; all $n=40$ ) or females (brightness: $r=-0.16, p=0.91$; hue: $r=0.013, p=0.93$; UV chroma: $r=0.08, p=0.56$; for all, $n=44$ ).

\section{Protein assays}

Each egg was cracked into a sterile petri dish, and its yolk and albumen were separated by manual pipetting into separate sterile tubes. To measure lysozyme concentration, we used a version of the lyso-plate method of Osserman and Lawlor (1966). We added $25 \mathrm{mg}$ dried Micrococcus lysodeikticus (Sigma, St. Louis, MO, USA) to $50 \mathrm{ml} 1 \%$ agar (Difco, Detroit, MI, USA) and kept the suspension at a temperature of $50-60^{\circ} \mathrm{C}$. Then this suspension was added to a small or medium size gel rig plate with combs for wells. Once dry, we added $10 \mu \mathrm{l}$ of albumen to every other well. Positive (chicken egg albumen) and negative (deionized water) controls were included with every plate. We obtained a standard curve by adding serial dilutions of a standard lysozyme solution (10 to $0.3125 \mathrm{mg} / \mathrm{ml}$ ) to the bottom row of each plate. Plates were incubated for $8 \mathrm{~h}$ at room temperature and then digitized using a scanner at 400 dpi. Width of the zones of clearing in the agar was measured from these digital images using ImageJ (available for download at http://rsbweb.nih.gov/ij/). Concentration of lysozyme in each sample was calculated by comparison of absorbance values to those of the standard curve.

We measured concentrations of ovotransferrin and avidin following the methods used by Shawkey et al. (2008). Briefly, to determine avidin concentrations, we used a colorimetric method based on the competitive binding between avidin, biotin, and horseradish peroxidase. To measure concentrations of ovotransferrin, we used the total iron binding capacity assay. This assay measures the amount of iron necessary to saturate ovotransferrin in the sample and thus correlates well with ovotransferrin (Yamanishi et al. 2002). To estimate repeatability of each assay, we measured ten samples five times each on ten different plates. 
All three assays were highly repeatable (lysozyme: $r=0.85$, $p<0.001$; avidin: $r=0.75, p<0.001$; ovotransferrin: $r=0.78$, $p<0.001)$. Due to limitations on the volume of albumen used for each assay in a few cases it was not possible to measure all three proteins for all eggs so final sample sizes of antimicrobial content were 170, 162, and 176 (of 44 clutches) eggs for lysozyme, avidin, and ovotransferrin, respectively.

\section{Statistical analyses}

Albumen lysozyme concentrations were not normally distributed (Kolmogorov-Smirnov test, $p<0.05$ ) and were log-transformed $(p=0.20)$ prior to using parametric tests. Avidin and ovotransferrin concentrations also deviated from normality, but transformation did not improve their distribution. Therefore, we employed linear models on the ranked variables (Conover and Iman 1981). Figures present non-transformed data.

To analyze within-clutch variation of antimicrobial proteins, we performed general linear mixed models using the "Ime" function in R software (V.2.3.1) with concentrations of lysozyme, avidin, or ovotransferrin as dependent variables, nest of origin as random factor and laying order, and clutch size as covariates. To assess the effect of male attractiveness and parental condition on antimicrobial investment, we used the mean concentration of lysozyme and avidin of each clutch. We obtained data from both parents in 40 out of the 44 clutches; thus our sample size for these analyses was 40 nests. For ovotransferrin, we used all egg values $(n=176)$ to account for variation related to laying sequence (see "Results" section). We fit a set of linear models with antimicrobial concentrations as the response variables for lysozyme and avidin, and linear mixed-effect models (procedure "lme") for ovotransferrin, which included nest identity and laying order as random effects.

The predictor variables used in the set of candidate models were age, mass, laying date, brightness, UV chroma, and hue for females and polygyny, age, mass, brightness, UV chroma, and hue for males. To reduce the number of predictors tested in each set of candidate models, we chose models in two steps. In a preliminary step, we evaluated a set of standard models with all single parameters from either males or females for all three antimicrobials. We ranked the models based on the Akaike's Information Criterion corrected for small sample size (AICc; Burnham and Anderson 2002) and variables which showed support from the data (models with a $\triangle \mathrm{AICc}<10$; Burnham and Anderson 2002) were kept and tested in the second step as part of the final candidate set for each antimicrobial. We evaluated 16 models in the final candidate set which included combinations of variables from both sexes (avoiding the inclusion of highly correlated variables in a same model). When more than one candidate model showed explanatory ability as indicated by an AICc value that differed from the best model (i.e., the one with the smallest AICc) by $\leq 2$, we model-averaged parameter estimates to get effect sizes (" $\theta$ ") and the associated variances from the $95 \%$ confidence set of candidate models (Burnham and Anderson 2002). Effects were considered significant when the $95 \%$ confidence interval did not include zero.

\section{Results}

Variation of lysozyme and avidin was unrelated to laying order (Fig. 1, Table 1). Only concentrations of ovotransferrin varied with laying sequence (Table 1) and this occurred in a quadratic fashion, with eggs laid early and late in the sequence showing lower ovotransferrin levels than eggs laid in the middle of the sequence (Fig. 1). Variation among females in concentration of lysozyme and avidin was significant (Table 1), but not for ovotransferrin (Table 2), and the interaction term with clutch size was never significant. Concentrations of lysozyme were not correlated with avidin ( $r=0.04, p=0.60, n=162$ eggs) or ovotransferrin levels $(r=$ $0.12, p=0.11, n=170$ eggs). Albumen concentrations of avidin and ovotransferrin were positively correlated $(r=0.21$, $p<0.01, n=162$ eggs). Egg mass was not correlated with concentrations of any of the antimicrobial proteins (lysozyme: $r=0.002, p=0.97$; avidin: $r=0.07, p=0.34$; ovotransferrin: $r=0.12, p=0.10$ ). Concentrations of antimicrobial proteins in egg albumen were highly variable (lysozyme: 0.65 \pm $0.76 \mathrm{SD} \mu \mathrm{g} / \mathrm{ml}$; avidin: $1.10 \pm 9.04 \mathrm{SD} \mu \mathrm{g} / \mathrm{ml}$; ovotransferrin: $26.81 \pm 35.61 \mathrm{SD} \mathrm{mg} / \mathrm{ml}$ ).

There was evidence that parental traits affected antimicrobial allocation to eggs. For lysozyme concentrations, male body mass, male UV chroma, polygyny, and female brightness occurred in the three most parsimonious models (Table 2). The top ranked model had a coefficient of determination (adjusted $R^{2}$ ) equal to 0.29 . Model-averaged parameter estimates showed that concentrations of lysozyme increased with male UV chroma ( $\theta$ : 8.671 95\% CI 4.45, 12.88; Fig. 2a) and were significantly lower in clutches in which the father was polygynous $(\theta$ : $-0.26295 \%$ CI $-0.481,-0.043$, Fig. 2b). However, lysozyme did not vary significantly with male body mass $(\theta$ : $-0.0890,95 \%$ CI $-0.180,0.002)$ or female brightness $(\theta: 0.002,95 \%$ CI $-0.002,0.008)$. UV chroma did not differ between polygynous $(n=5)$ and monogamous $(n=35)$ males $(t=0.132, p=0.24)$.

None of the predictors produced a model with high explanatory power for concentration of avidin (Table 2), and the top ranked model had a low adjusted $R^{2}(=0.005)$. Concentrations of avidin did not vary with any of the variables included in the three top models: male age $(\theta$ : $-0.37695 \%$ CI $-0.815,0.438)$, male UV chroma ( $\theta: 1.69$ $95 \% \mathrm{CI}-20.16,23.54)$, and male mass $(\theta: 0.01195 \% \mathrm{CI}$ 

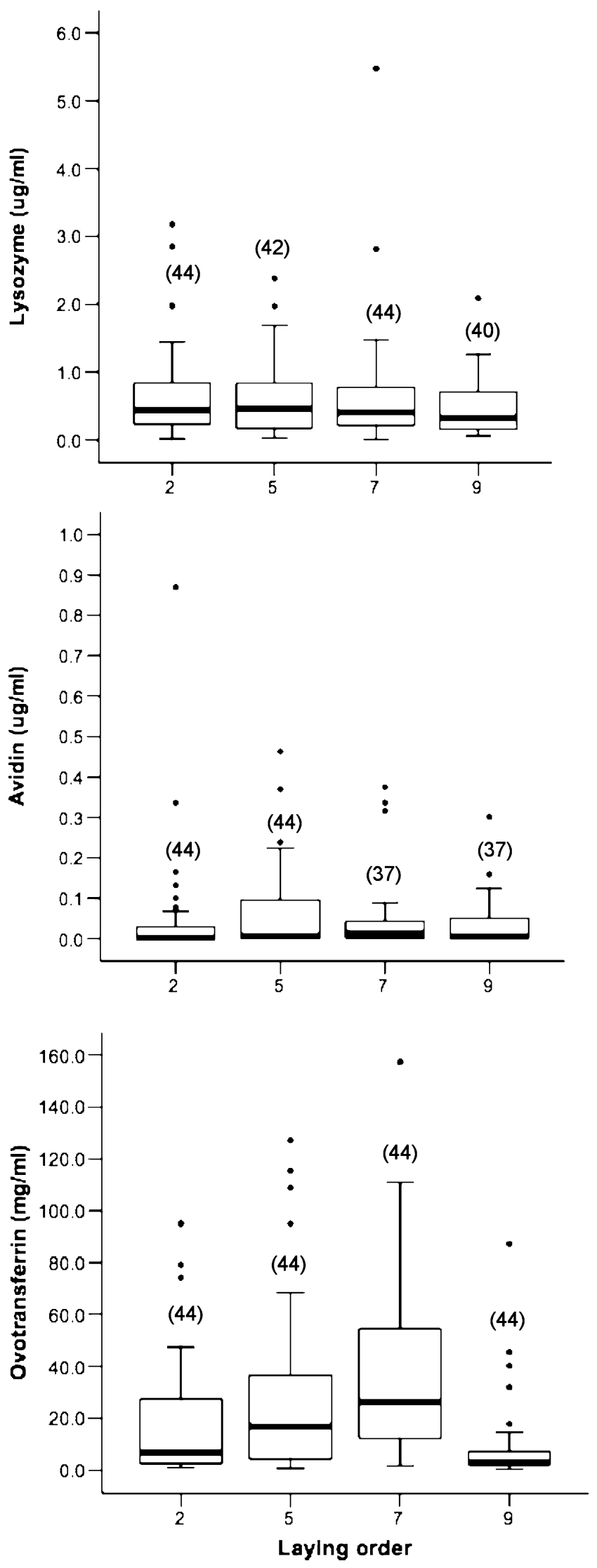

Fig. 1 Concentration of antimicrobial proteins by laying order in blue tit eggs. The line within each box represents the median concentration, the lower and upper borders are the 25th and 75th percentiles, and the lower and upper bars are the tenth and 90th percentiles. Sample sizes are in parenthesis at the top of each box. Outliers (values between 1.5 and 3 from the interquartile range) are represented with circles

$-0.019,0.020)$. The best model for concentrations of ovotransferrin included only male UV chroma (Table 2). However, ovotransferrin did not change substantially with UV chroma ( $\theta$ : $-0.605,95 \%$ CI $-9.677,8.467)$.

We evaluated whether the increased deposition of lysozyme with male UV chroma could have been caused by correlations between male and female phenotypes. We found strong assortative mating by age; first-year breeders were paired to other new breeders $\left(\chi^{2}=9.01, \mathrm{df}=1, p=0.003, n=40\right.$ males and 40 females). However, there was no significant correlation between males and females for any parameter of body size or plumage coloration (all $p>0.10$ ), as previously reported for this population (Korsten 2006). Older females (mean: $0.24 \pm 0.004 \mathrm{SE}, n=17$ ) had significantly higher UV chroma $(t=2.93, p=0.007)$ than younger females (mean: $0.22 \pm 0.002 \mathrm{SE}, n=27)$. There was no significant difference $(t=1.43, p=0.17, n=40)$ in UV chroma between young and old males (young: mean $=0.268 \pm 0.003 \mathrm{SE}, n=28$; old: mean $=0.275 \pm 0.005 \mathrm{SE}, n=12$ ).

\section{Discussion}

We found that differential allocation of antimicrobial proteins to blue tit eggs occurred both within and among clutches. We found little support for variation in antimicrobials in relation to laying order, as predicted by the "exposure hypothesis." We did not find any sequence effect for lysozyme and avidin, but allocation of ovotransferrin to eggs varied with laying order in a quadratic fashion. The quadratic distribution of ovotransferrin, with lower concentrations in early- and late- than in middle-laid eggs, does not support our hypothesis that withinclutch variation of antimicrobials should be highest in firstlaid eggs that are exposed longer to ambient conditions prior to the onset of full incubation. Perhaps a strong evolutionary constraint prevents females from optimally adjusting the deposition of antimicrobial proteins in relation to laying order, or perhaps there is little risk of infection by microbes in the temperate environment experienced by tits prior to the onset of full incubation to select for differential allocation. In addition, we did not find any significant relationship between overall antimicrobial content and female condition (e.g., the final model in Table 2) suggesting that it is unlikely that females in worse condition differentially allocate antimicrobials to eggs while those in good condition do not.

The observed pattern in ovotransferrin levels may also be a non-adaptive side-effect of, for example, hormone- 
Table 1 Mixed-effect model of concentrations of antimicrobial proteins in the albumen of 176 blue tit eggs. laying order (LO), its quadratic effect $\left(\mathrm{LO}^{2}\right)$ and clutch size $(\mathrm{CS})$ were modeled as fixed effects, and nest of origin (Nest ID, $n=44$ ) as a random effect

\begin{tabular}{|c|c|c|c|c|c|c|c|c|c|}
\hline \multirow[b]{2}{*}{ Parameter } & \multicolumn{3}{|c|}{ Lysozyme } & \multicolumn{3}{|c|}{ Avidin } & \multicolumn{3}{|c|}{ Ovotransferrin } \\
\hline & df & F & $\mathrm{P}$ & $\mathrm{df}$ & $\mathrm{F}$ & $\mathrm{P}$ & df & $\mathrm{F}$ & $\mathrm{P}$ \\
\hline LO & 3,159 & 0.30 & 0.82 & 3,149 & 1.85 & 0.14 & 3,133 & 11.56 & $<0.01$ \\
\hline $\mathrm{LO}^{2}$ & 3,159 & 0.79 & 0.50 & 3,149 & 0.99 & 0.39 & 3,133 & 12.76 & $<0.01$ \\
\hline $\mathrm{CS}$ & 1,159 & 1.08 & 0.30 & 1,151 & 2.01 & 0.15 & 1,133 & 0.10 & 0.75 \\
\hline $\mathrm{LO} \times \mathrm{CS}$ & 3,159 & 0.24 & 0.86 & 3,151 & 1.94 & 0.12 & 3,133 & 0.60 & 0.61 \\
\hline Nest ID Wald Z: & \multicolumn{3}{|c|}{$2.05, p=0.04$} & \multicolumn{3}{|c|}{$8.68, p<0.01$} & \multicolumn{3}{|c|}{$0.06, p=0.97$} \\
\hline
\end{tabular}

induced changes in the female reproductive tract during the formation of the clutch.

Albumen proteins are synthesized in the magnum portion of the oviduct under control of steroid hormones (Palmiter 1972). Plasma estrogen is transported to the oviduct where it activates the differentiation and proliferation of cells that produce egg white proteins. Because plasma hormone levels change during the laying cycle (Etches 1996), early and late developing follicles may be exposed to very different hormonal environments during egg formation (Williams et al. 2005). For example, in blue tits a similar pattern has been observed for the deposition of testosterone in eggs in relation to laying order (Kingma et al. 2009). In female starlings (Sturnus vulgaris) plasma estradiol has been reported to also follow a bell-shaped curve, increasing from the onset of yolk development and then decreasing linearly with later follicle development (Williams et al. 2004). If estrogen binding by receptors in oviductal cells mirrors this pattern, hormonal changes in the laying female could potentially result in a laying sequence pattern of albumen protein deposition like that observed in our study. This would indicate that females are unable to tailor albumen quality independently of their plasma androgen levels, as has been suggested for the deposition of androgens to egg yolks (Birkhead et al. 2000, Williams et al. 2005).

That we did not observe the same result for lysozyme and avidin could be because additional hormones (e.g.,
Table 2 General linear models of lysozyme and avidin $(n=40$ clutches) and mixed model of ovotransferrin concentrations $592(n=$ 176 eggs $)$ in blue tit eggs. The number of estimated parameters $(k$, including the intercept and error terms), difference in AICc relative to the top model $(\triangle \mathrm{AICc})$, and Akaike weights $(w)$ are shown for each model. Two additional parameters were considered in ovotransferrin models to account for the random effects. Female predictor variables include age (FAGE), mass (FMASS), brightness (FBRI), UV chroma (FUVCHROM), HUE (FHUE), clutch size (CS), and laying date (LD). Male predictor variables include polygyny (POL), age (MAGE), mass (MMASS), brightness (MBRI), UV chroma (MUVCHROM), and hue (MHUE). Bold numbers denote the top-ranked models (with the smallest $\mathrm{AIC}+\leq 2$ )

\begin{tabular}{|c|c|c|c|c|c|c|c|c|c|c|}
\hline \multirow[t]{2}{*}{ MODEL } & \multirow[t]{2}{*}{$\mathrm{k}$} & \multicolumn{3}{|c|}{ LYSOZYME } & \multicolumn{3}{|c|}{ OVOTRANSFERRIN } & \multicolumn{3}{|c|}{ AVIDIN } \\
\hline & & Rank & $\triangle A I C c$ & $w$ & Rank & $\triangle A I C c$ & Weight & Rank & $\triangle A I C c$ & $w$ \\
\hline POL+MMASS+MUVCHROM & 5 & 1 & 0.00 & 0.35 & 5 & 8.02 & 0.01 & 7 & 4.35 & 0.03 \\
\hline POL+FBRI+MMASS+MUVCHROM & 6 & 2 & 1.68 & 0.15 & 8 & 14.76 & 0.00 & 5 & 3.07 & 0.06 \\
\hline MMASS+MUVCHROM & 4 & 3 & 1.72 & 0.15 & 3 & 4.04 & 0.09 & 2 & 0.82 & 0.20 \\
\hline MUVCHROM & 3 & 4 & 2.45 & 0.10 & 1 & 0.00 & 0.66 & 4 & 1.81 & 0.12 \\
\hline FBRI & 3 & 5 & 3.03 & 0.08 & 2 & 2.28 & 0.21 & 13 & 17.62 & 0.00 \\
\hline POL+MMASS+MBRI+MUVCHROM & 6 & 6 & 3.36 & 0.06 & 10 & 19.32 & 0.00 & 8 & 4.69 & 0.03 \\
\hline FMASS+FBRI & 4 & 7 & 4.31 & 0.04 & 9 & 16.62 & 0.00 & 10 & 6.79 & 0.01 \\
\hline FMASS+FBRI+POL+MMASS+MUVCHROM & 7 & 8 & 4.58 & 0.04 & 13 & 25.68 & 0.00 & 15 & 20.34 & 0.00 \\
\hline FHUE & 3 & 9 & 6.20 & 0.02 & 6 & 10.36 & 0.00 & 12 & 16.68 & 0.00 \\
\hline POL+MAGE+MMASS+MBRI+MUVCHROM & 7 & 10 & 7.11 & 0.01 & 12 & 20.74 & 0.00 & 6 & 3.87 & 0.04 \\
\hline LD+FHUE & 4 & 11 & 8.64 & 0.00 & 11 & 19.62 & 0.00 & 14 & 17.81 & 0.00 \\
\hline MAGE+MMASS & 4 & 12 & 9.57 & 0.00 & 4 & 6.57 & 0.02 & 1 & 0.00 & 0.30 \\
\hline $\mathrm{POL}+\mathrm{MAGE}+\mathrm{MMASS}+\mathrm{MBRI}$ & 6 & 13 & 10.76 & 0.00 & 14 & 27.08 & 0.00 & 11 & 7.94 & 0.01 \\
\hline MAGE & 3 & 14 & 11.43 & 0.00 & 7 & 10.72 & 0.00 & 3 & 1.01 & 0.18 \\
\hline POL+MAGE+MMASS & 5 & 15 & 13.75 & 0.00 & 15 & 27.44 & 0.00 & 9 & 6.46 & 0.01 \\
\hline FMASS+CL+FAGE+FBRI+FUVCHROM & 7 & 16 & 14.44 & 0.00 & 16 & 28.60 & 0.00 & 16 & 26.10 & 0.00 \\
\hline
\end{tabular}




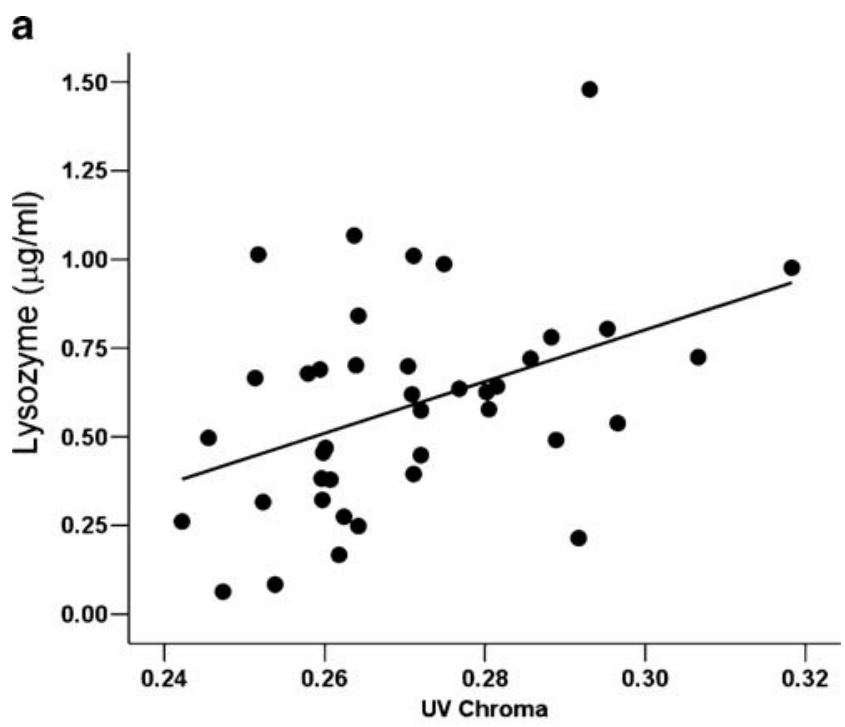

b

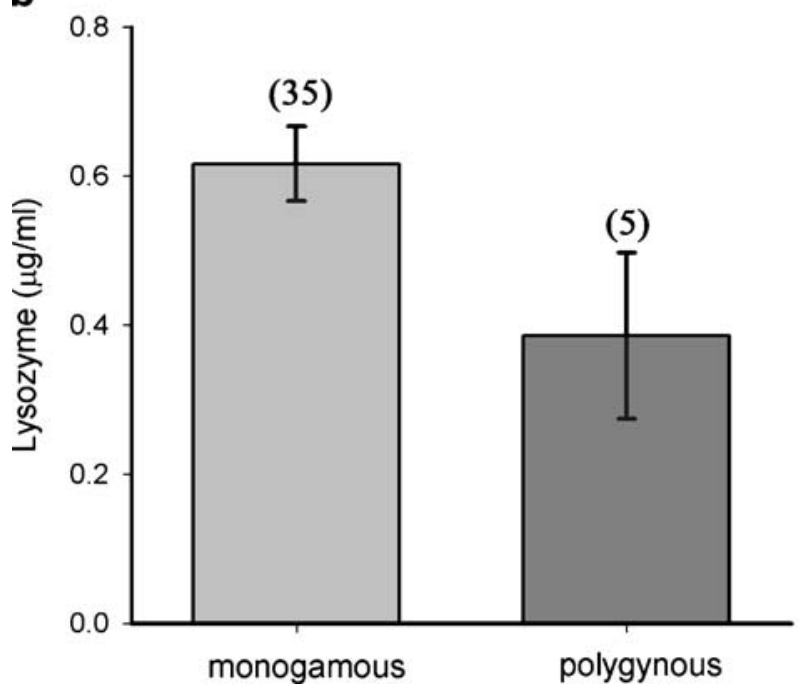

Fig. 2 Concentration of lysozyme in albumen of blue tit clutches $(\mathrm{n}=40)$ in relation to a male UV chroma $(r=0.42, p=0.007)$ and b mating system $(t=2.16, p=0.04)$. Correlation between lysozyme concentration and UV chroma remain significant even after excluding the two most extreme data points $(r=0.35, p=0.02)$. The error bars represent means \pm 1 standard error. Sample sizes are in parentheses

progesterone for avidin synthesis) or different concentrations of estrogen might regulate the production of specific albumen proteins (Palmiter 1972). Although lysozyme and ovotransferrin are present in uterine fluid during all phases of egg production (Gautron et al. 1997), it is unknown whether deposition of antimicrobial proteins to eggs is the result of a simple diffusion or whether there is a mechanism that allows fine control of the deposition of lysozyme. Neither is there evidence that there are any physiological costs for the deposition of antimicrobials in the albumen (Shawkey et al. 2008). An experimental approach may be able to determine the temporal scale at which changes in deposition of antimicrobials might occur during egg formation (see, Kingma et al. 2009 for an example of such an approach for yolk hormones).

Females increased the amount of lysozyme they transferred to their eggs when mated to a more attractive male (higher UV chroma) and variation of lysozyme and avidin among clutches was significant (Table 1; Figs. 1 and 2). This result is consistent with the differential allocation hypothesis (Burley 1986; Sheldon 2000). The correlation may reflect a response to the likely direct or indirect benefits that attractive males might provide for females by increasing the value of the given reproductive attempt. Further experiments manipulating male UV reflectance are needed to test this hypothesis.

Some studies in blue tits have shown that females adjust their reproductive effort as a function of the attractiveness of the male they are paired with (e.g., Limbourg et al. 2004; Johnsen et al. 2005). Furthermore, some of those studies have shown that females vary their investment in specific components of eggs, for example carotenoids (Szigeti et al. 2007) and androgens (Kingma et al. 2009). To our knowledge, this is the first investigation of differential maternal investment in egg antimicrobial defense in relation to male attractiveness. Lysozyme defends the embryo from bacterial infection, but may also play an important role complementing the immune system of chicks during the first days after hatching (Saino et al. 2002). Therefore, the DAH may suggest that females mated to attractive males would favor their offspring by providing them with more antimicrobial protection. Further research on the cost of the deposition of antimicrobial proteins in eggs and their benefits to offspring health and survival is needed to test this hypothesis, as well as experimental manipulations of male attractiveness.

An causal explanation for the observed differential allocation of lysozyme to clutches that we observed is that it is an epiphenomenon of the influence of attractive male traits on the hormonal state of females. An elevation in the production of lysozyme by tubular gland cells of the oviduct can be induced by increases in estrogen and progesterone (Palmiter 1972). Female blue tits could respond to male attractiveness by increasing plasma estrogen levels, which has been shown in female canaries (Serinus canaria) that elevate circulating estrogen after exposure to attractive male songs (Marshall et al. 2005).

Contrary to our prediciton, females produced clutches with lower concentrations of lysozyme when mated to polygynous males. This could be explained if prospects of being deserted increase with polygyny (Trivers 1972). Alternatively, females may perceive a lower disposition in polygynous males to invest in paternal care. For example, blue tit females mated to polygynous males receive reduced (primary female) or no assistance (secondary female) from their partners during chick rearing in comparison with monogamous females (Kempenaers 1995). Females may 
compensate for reduced parental investment of polygynous males by producing larger eggs (Kempenaers 1995). Females may also trade off additional nutrients or vitamins against antimicrobial proteins in eggs sired by polygynous males. Examination of total albumen content, including proteins, water, and vitamins, will allow us to test this hypothesis. Furthermore, examination of the antimicrobial activity of total albumen, including all of the antimicrobial proteins and other agents it contains, will also be an exciting prospect for future study.

Overall, our results demonstrate that variation in antimicrobial concentration in blue tits occurs both within and among clutches. In the latter case this may represent increased female provisioning of antimicrobial protection to eggs sired by attractive males. However, despite the large body of evidence showing the antimicrobial properties of albumen proteins in studies in vitro, our knowledge about the fitness consequences of the deposition of these compounds to the eggs of wild species is almost negligible. For example, does hatchability improve with higher concentrations of antimicrobials? Does antimicrobial deposition to eggs increase in environments with high exposure to pathogens? To answer these questions, future research should examine the fitness consequences of variation in antimicrobial defenses of avian eggs. It is also essential to assess both, the total bactericidal capacity of albumen and the capacity of its different components, paying particular attention to the environmental and ecological factors that influencing variation in albumen quality and protection from microbial infection.

Acknowledgments We thank the "Kraus-Groeneveld" Foundation for permission to work at estate "De Vosbergen." Fieldwork was greatly assisted by Marije Oostindjer and Linda Wester. This research was financially supported by The Netherlands Organisation for Scientific Research (NWO; ALW grant 810.67.022 to JK), the U.S. National Science Foundation (IOB-0517549 to SRB), a Glasgow Natural History Society research grant to LDA, and the U.S. Air Force Office of Scientific Research (FA9550-09-1-0159 to MDS).

Conflict of interest The authors declare that they have no conflict of interest.

Open Access This article is distributed under the terms of the Creative Commons Attribution Noncommercial License which permits any noncommercial use, distribution, and reproduction in any medium, provided the original author(s) and source are credited.

\section{References}

Andersson M (1994) Sexual selection. Princeton University Press, New Jersey

Andersson S, Örnborg J, Andersson M (1998) Ultraviolet sexual dimorphism and assortative mating in blue tits. Proc R Soc Lond B 265:445-450
Arnold TW, Rohwer FC, Armstrong T (1987) Egg viability, nest predation and the adaptive significance of clutch size in Prairie Ducks. Am Nat 130:643-653

Beissinger SR, Cook MI, Arendt WJ (2005) The shelf life of bird eggs: testing egg viability using a tropical climate gradient. Ecology $86: 2164-2175$

Birkhead T, Schwabl H, Burke T (2000) Testosterone and maternal effects - integrating mechanisms and function. Trends Ecol Evol 15:86-87

Board RG, Fuller R (1974) Non-specific antimicrobial defences of avian egg embryo and neonate. Biol Rev 49:15-49

Board RG, Clay CE, Dolman J, Lock JL (1994) The egg: a compartmentalized aseptically packaged food. In: Board RG, Fuller R (eds) Microbiology of the avian egg. Chapman \& Hall, London

Burley N (1986) Sexual selection for aesthetic traits in species with biparental care. Am Nat 127:415-445

Burley N (1988) The differential-allocation hypothesis - an experimental test. Am Nat 132:611-628

Burnham KP, Anderson DR (2002) Model selection and multimodel inference: a practical information-theoretic approach, 2nd edn. Springer-Verlag New York, New York

Christians JK (2002) Avian egg size: variation within species and inflexibility within individuals. Biol Rev 77:1-26

Conover WJ, Iman RL (1981) Rank transformations as a bridge between parametric and nonparametric statistics. Am Stat $35: 124-129$

Cook MI, Beissinger SR, Toranzos GA, Rodriguez RA, Arendt WJ (2003) Trans-shell infection by pathogenic micro-organisms reduces the shelf life of non-incubated bird's eggs: a constraint on the onset of incubation? Proc R Soc Lond B 270:2233-2240

Cook MI, Beissinger SR, Toranzos GA, Arendt WJ (2005a) Incubation reduces microbial growth on eggshells and the opportunity for trans-shell infection. Ecol Lett 85:532-537

Cook MI, Beissinger SR, Toranzos GA, Rodriguez RA, Arendt WJ (2005b) Microbial infection affects egg viability and incubation behavior in a tropical passerine. Behav Ecol 16:30-36

Cunningham EJA, Russell AF (2000) Egg investment is influenced by male attractiveness in the mallard. Nature 404:74-77

Delhey K, Johnsen A, Peters A, Andersson S, Kempenaers B (2003) Paternity analysis reveals opposing selection pressures on crown coloration in the blue tit Parus caeruleus. Proc R Soc Lond B 270:2057-2063

Dhondt AA, Eyckerman R, Schillemans J (1983) Polygyny by blue tits. Br Birds 76:34-37

Etches RJ (1996) Reproduction in poultry. CAB International, Oxford

Gautron J, Hincke MT, Nys Y (1997) Precursor matrix proteins in the uterine fluid change with stages of eggshell formation in hens. Connect Tissue Res 36:195-210

Gil D, Graves J, Hazon N, Wells A (1999) Male attractiveness and differential testosterone investment in zebra finch eggs. Science 286:126-128

Griffith SC, Örnborg J, Russell AF, Andersson S, Sheldon BC (2003) Correlations between ultraviolet coloration overwinter survival and offspring sex ratio in the blue tit. J Evol Biol 16:1045-1054

Hart NS, Partridge JC, Cuthill IC, Bennett ATD (2000) Visual pigments oil droplets ocular media and cone photoreceptor distribution in two species of passerine bird: the blue tit Parus caeruleus $L$ and the blackbird Turdus merula L. J Comp Physiol A $186: 375-387$

Johnsen A, Delhey K, Schlicht E, Peters A, Kempenaers B (2005) Male sexual attractiveness and parental effort in blue tits: a test of the differential allocation hypothesis. Anim Behav 70:877-888

Kempenaers B (1993) A case of polyandry in the blue tit: female extra-pair behaviour results in extra male help. Ornis Scand $24: 246-249$ 
Kempenaers B (1994) Polygyny in the blue tit: unbalanced sex ratio and female aggression restrict mate choice. Anim Behav 47:943-957

Kempenaers B (1995) Polygyny in the blue tit: intra- and inter-sexual conflicts. Anim Behav 49:1047-1064

Kingma SA, Komdeur J, Vedder O, von Engelhardt N, Korsten P, Groothuis TGG (2009) Manipulation of male attractiveness induces rapid changes in avian maternal yolk androgen deposition. Behav Ecol 20:172-179

Korsten P (2006) Avian sex allocation and ornamental coloration - a study on blue tits $\mathrm{PhD}$ dissertation University of Groningen pp 19 (URL: irs.ub.rug.nl/ppn/298509423)

Korsten P, Lessells C, Mateman AC, van der Velde M, Komdeur J (2006) Primary sex ratio adjustment to experimentally reduced male UV attractiveness in blue tits. Behav Ecol 17:539-546

Korsten P, Vedder O, Szentirmai I, Komdeur J (2007) Absence of status signalling by structurally based ultraviolet plumage in wintering blue tits (Cyanistes caeruleus). Behav Ecol Sociobiol 61:1933-1943

Kowalczyk K, Daiss J, Halpern J, Roth TF (1985) Quantification of maternal-fetal IgG transport in the chicken. Immunology 54:755-762

Li-Chan EC, Powrie WD, Nakai S (1995) The chemistry of eggs and egg products. In: Stadelman WJ, Cotterill OJ (eds) Egg science and technology. The Haworth Press, Binghamton, pp 105-175

Limbourg T, Mateman AC, Andersson S, Lessells C (2004) Female blue tits adjust parental effort to manipulated male UV attractiveness. Proc R Soc Lond B 271:1903-1908

Loyau A, Saint Jalme M, Mauget R, Sorci G (2007) Male sexual attractiveness affects the investment of maternal resources into the eggs in peafowl Pavo cristatus. Behav Ecol Sociobiol 61:1043-1052

Magrath MJL, Vedder O, van der Velde M, Komdeur J (2009) Maternal effects contribute to the superior performance of extrapair offspring. Curr Biol 19:792-797

Marshall RC, Leisler B, Catchpole CK, Schwabl H (2005) Male song quality affects circulating but not yolk steroid concentrations in female canaries Serinus canaria. J Exp Biol 208:4593-4598

Mousseau T, Fox CW (1998) Maternal Effects as adaptations. Oxford university Press, Oxford

Nilsson J-A (2000) Time-dependent reproductive decisions in the blue tit. Oikos 88:351-361

Osserman EF, Lawlor DP (1966) Serum and urinary lysozyme muramidase in monocytic and monomyelocytic leukaemia. J Exp Med 124:921-952

Palmiter RD (1972) Regulation of protein synthesis in chick oviduct I independent regulation of ovalbumin, conalbumin, ovomcoid and lysozyme induction. J Biol Chem 247:6450-6461

Petrie M, Williams A (1993) Peahens lay more eggs for peacocks with larger trains. Proc R Soc Lond B Biol Sci 251:127-131

Ramsey SL, Houston DC (1998) The effect of dietary amino acid composition on egg production in the blue tit. Proc R Soc Lond B 265:1401-1405

Reynolds SJ, Schoech SJ, Bowman R (2003) Nutritional quality of prebreeding diet influences breeding performance of the Florida scrub-jay. Oecologia 134:308-316

Rogers HJ, Perkins HR (1968) Cell walls and membranes. Spon, London
Saino N, Dall'ara P, Martinelli R, Moller AP (2002) Early maternal effects and antibacterial immune factors in the eggs nestlings and adults of the barn swallow. J Evol Biol 15:735-743

Shawkey MD, Kosciuch KL, Liu M, Rohwer FC, Loos ER, Wang JM, Beissinger SR (2008) Do birds differentially distribute antimicrobial proteins within clutches of eggs? Behav Ecol 19:920-927

Shawkey MD, Firestone MK, Brodie EL, Beissinger SR (2009) Avian incubation inhibits growth and diversification of bacterial assemblages on eggs. PLoS ONE 4:e4522

Sheldon BC (2000) Differential allocation: tests mechanisms and implications. Trends Ecol Evol 15:397-402

Sheldon BC, Andersson S, Griffith SC, Ornborg J, Sendecka J (1999) Ultraviolet colour variation influences blue tit sex ratios. Nature 402:874-877

Stoleson S, Beissinger SR (1999) Egg viability as a constraint on hatching synchrony at high ambient temperatures. J Anim Ecol 68:951-962

Svensson L (1992) Identification guide to European passerines. Fingraf, Stockholm, p 368

Szigeti B, Török J, Hegyi G, Rosivall B, Szõllõsi E, Michl G (2007) Egg quality and parental ornamentation in the blue tit Parus caeruleus. J Avian Biol 38:105-112

Tranter HS, Board RG (1982) The antimicrobial defence of avian eggs: biological perspective and chemical basis. J Appl Biochem $4: 295-338$

Trivers RL (1972) Parental investment and sexual selection. In: Campbell B (ed) Sexual selection and the descent of man 18711971. Aldine-Atherton, Chicago, pp 136-179

Velando A, Beamonte-Barrientos R, Torres R (2006) Pigment-based skin colour in the blue-footed booby: an honest signal of current condition used by females to adjust reproductive investment. Oecologia 149:535-542

Verboven N, Evans NP, D'Alba L, Nager RG, Blount JD, Surai PF, Monaghan P (2005) Intra-specific interactions influence egg composition in the lesser black-backed gull Larus fuscus. Behav Ecol Sociobiol 57:357-365

Williams TD (1994) Intraspecific variation in egg size and egg composition in birds: effects on offspring fitness. Biol Rev 68:35-59

Williams TD (2005) Mechanisms underlying the costs of egg production. Bioscience 55:39-48

Williams TD, Kitaysky AS, Vézina F (2004) Individual variation in plasma estradiol-17b and androgen levels during egg formation in the European starling Sturnus vulgaris: implications for regulation of yolk steroids. Gen Comp Endocrinol 136:346-352

Williams TD, Ames CE, Kiparissis Y, Wynne-Edwards KE (2005) Laying-sequence-specific variation in yolk oestrogen levels and relationship to plasma oestrogen in female zebra finches Taeniopygia guttata. Proc R Soc Lond B Biol Sci 272:173-177

Williamson KA, Surai PF, Graves JA (2006) Yolk antioxidants and mate attractiveness in the Zebra Finch. Funct Ecol 20:354-359

Yamanishi H, Iyama S, Yamaguchi Y, Kanakura Y, Iwatani Y (2002) Modification of fully automated total iron-binding capacity TIBC assay in serum and comparison with dimension TIBC method. Clin Chem 48:1565-1570 